\title{
The response of Mediterranean thermohaline circulation to climate change: a minimal model
}

\author{
P. Th. Meijer ${ }^{1}$ and H. A. Dijkstra ${ }^{2}$ \\ ${ }^{1}$ Department of Earth Sciences, Faculty of Geosciences, Utrecht University, The Netherlands \\ ${ }^{2}$ Institute for Marine and Atmospheric Research Utrecht, Utrecht University, The Netherlands \\ Received: 17 June 2009 - Published in Clim. Past Discuss.: 30 June 2009 \\ Revised: 20 October 2009 - Accepted: 3 November 2009 - Published: 19 November 2009
}

\begin{abstract}
Physics-based understanding of the effects of paleoclimate and paleogeography on the thermohaline circulation of the Mediterranean Sea requires an ocean model capable of long integrations and involving a minimum of assumptions about the atmospheric forcing. Here we examine the sensitivity of the deep circulation in the eastern Mediterranean basin to changes in atmospheric forcing, considered a key factor in the deposition of organic-rich sediments (sapropels). To this extent we explore the setup of an ocean general circulation model (MOMA) with realistic (present-day) bathymetry and highly idealized forcing. The model proves able to qualitatively capture some important features of the large-scale overturning circulation, in particular for the eastern basin. The response to (i) a reduction in the imposed meridional temperature gradient, or (ii) a reduction in net evaporation, proves to be non-linear and, under certain conditions, of transient nature. Consistent with previous model studies, but now based on a minimum of assumptions, we find that a reduction in net evaporation (such as due to an increase in freshwater input) may halt the deep overturning circulation. The ability to perform long model integrations allows us to add the insight that, in order to have the conditions favourable for sapropel formation persist, we must also assume that the vertical mixing of water properties was reduced. The "minimal" model here presented opens the way to experiments in which one truly follows the basin circulation into, or out of, the period of sapropel formation and where forcing conditions are continously adjusted to the precession cycle.
\end{abstract}

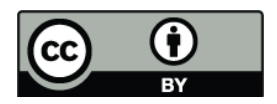

Correspondence to: $\mathrm{P}$. Th. Meijer (meijer@geo.uu.nl)

\section{Introduction}

The sedimentary record of the Mediterranean basin provides us with valuable information about the interactions between climate, ocean circulation, and sedimentation. One of the outstanding issues concerns the response of overturning circulation to increased freshwater flux to the sea surface. Such a response is thought evidenced by the regular intercalation of organic-rich sediments - sapropels - in the Neogene record of, in particular, the eastern Mediterranean basin (reviews of the extensive literature on this subject are given by Rohling, 1994; Cramp and O'Sullivan, 1999; Meyers, 2006; Emeis and Weissert, 2009). Sapropels coincide with precession-controlled climatic states (Hilgen, 1991; Lourens et al., 1996) which are known to involve an increase of freshwater input to the Mediterranean sea (e.g., Tuenter et al., 2003). This, through its stabilizing effect on the water column, has been suggested to weaken ventilation of the deeper layers and contribute to the conditions favourable for sapropel formation, probably in combination with changes in organic production and preservation (Rossignol-Strick, 1987; Rohling and Hilgen, 1991). Although interesting enough in its regional context, this mechanism is worth studying also because it is similar to the process that affected and, perhaps, will again affect, the Atlantic Ocean at the high latitudes (e.g., Schiermeier, 2006; Toggweiler and Russell, 2008).

Whereas general circulation models for the present-day Mediterranean Sea naturally tend to ever higher spatial resolution and realism of forcing, investigation of the Mediterranean overturning in the geological past requires a different approach. Understanding the effects of paleoclimate calls for a model with relatively coarse resolution suitable for long run times. Also, given the lack of detailed information on the past atmospheric forcing, one would like to explore to

Published by Copernicus Publications on behalf of the European Geosciences Union. 
which extent a model with "minimal" atmospheric forcing is still meaningful. A simplified model has the benefit of allowing to focus on the aspects of first-order importance. It is remarkable that idealized general circulation models have been widely applied to the thermohaline circulation of the world ocean for both the present (e.g., Rahmstorf, 1995) and the past (e.g., von der Heydt and Dijkstra, 2008) but not yet to the Mediterranean Sea. Non-idealized model studies aimed at the sapropels are in particular those of Myers et al. (1998) and Stratford et al. (2000) (see also Myers, 2002).

The purpose of this paper is twofold. Firstly, we introduce a model setup with realistic present-day bathymetry and strongly idealized atmospheric forcing and show that the model captures major features of the large-scale circulation, in particular for the eastern sub-basin. Secondly, we investigate the response of the deep circulation in the eastern basin to climate change. Here, the emphasis is on changes in atmospheric forcing that could potentially lead to a slow-down or termination of the deep overturning.

\section{Model description}

As a basis for our study we use the version of the Modular Ocean Model Array (MOMA; Webb, 1996) tailored to the Mediterranean Sea by Keith Haines and colleagues (Haines and $\mathrm{Wu}, 1998)$ and, at the time, made available to the community as part of the MedNet project. Whereas we will here focus on the use of idealized atmospheric forcing, the Mediterranean-MOMA implementation has been extensively studied in realistic setup, mainly by others (see Myers and Haines, 2002 and references therein) and in small part by ourselves (Meijer et al., 2004; Meijer and Tuenter, 2007). The bathymetry here adopted, at a resolution of $1 / 4$ by $1 / 4$ degree, is the one provided with the code and goes back to Roussenov et al. (1995). The model comprises 19 layers, spaced more closely near the surface than at depth. West of the Strait of Gibraltar the grid includes a small "Atlantic box" in which temperature and salinity are relaxed to the observed annual-mean, present-day fields (taken from the Levitus atlas). The rest of our setup deviates from the original MedNet model.

The surface freshwater forcing is idealized to a constant and uniform net evaporation (i.e., evaporation minus precipitation and river discharge, E-P-R), equal to $0.5 \mathrm{~m} / \mathrm{yr}$ in the reference experiment (this choice of value is discussed below). This boundary condition is implemented in the form of an equivalent salt flux using the modeled sea surface salinity. The surface heat flux is defined by means of relaxation to a constant atmospheric temperature which varies only with the cosine of latitude (Fig. 1). This approximates the zonally averaged, annual-mean field observed at present. In the reference experiment the relaxation time scale is $2 \mathrm{~h}$ (the MedNet value; we experimented with less strong relaxation as well, see below). Our choice to use a relaxation to atmo- spheric temperature and prescribed freshwater flux was inspired by successful global-scale idealized models such as that of Rahmstorf (1995). Finally, in most of the experiments, we ignore the presence of winds. Although not emphasized in this paper, we hope to arrive at a model setup suitable also for times in the past when Mediterranean geography was very different. Since present-day winds over the Mediterranean Sea are strongly controlled by the modern geography, in particular the distribution of mountains surrounding the sea, it is not justified to use the present wind field. Moreover, given that the spatial scale of these mountains is small compared to the grid size of most climate models, the wind field in the past is not readily estimated by such coupled models either. We thus set out to explore what can be achieved without the application of winds (but the effect of neglecting wind stress will be pointed out where appropriate).

Sub-gridscale processes are represented in the simplest of ways, using constant and uniform diffusional parameters. We adopt the values used by Roussenov et al. (1995; see also Meijer et al., 2004). Unless indicated otherwise a given experiment is started from uniform initial temperature and salinity (respectively, $16^{\circ} \mathrm{C}$ and $36 \mathrm{psu}$ ) and is run for at least 1000 years by which time equilibrium has been reached. Model integrations of 100-500 years have been done before for the Mediterranean Sea (Myers, 2002; Myers and Haines, 2002; Pisacane et al., 2006; Skliris et al., 2007). Invariably, however, the atmospheric forcing in these experiments, as in our own previous efforts, contains a strong imprint of the present-day pattern and values of sea surface properties or air-sea fluxes. This is not optimal when the aim is to understand the past Mediterranean circulation when the situation was possibly very different from the present.

\section{Model analysis}

\subsection{Reference experiment}

The residence time of the present Mediterranean basin is on the order of 100 years. In the reference experiment, after about 500 years, the basin-averaged kinetic energy, temperature and salinity have largely stabilized (Fig. 2; results have been confirmed by even longer integrations, up to 2000 years). While the final average temperature proves to lie close to the initial value, average salinity is elevated due to the steady evaporation. Both the final mean temperature $\left(16.4^{\circ} \mathrm{C}\right)$ and mean salinity $(39.4 \mathrm{psu})$ are higher than observed at present (respectively, $13.9^{\circ} \mathrm{C}$ and $38.6 \mathrm{psu}$ ). This result proves independent of the adopted initial temperature and salinity. For example, a run starting from an initial temperature equal to the temperature at depth in the Atlantic box (a temperature as low as $10^{\circ} \mathrm{C}$ ) gives, already after 200 years, about the same mean temperature as one started from $16^{\circ} \mathrm{C}$. 


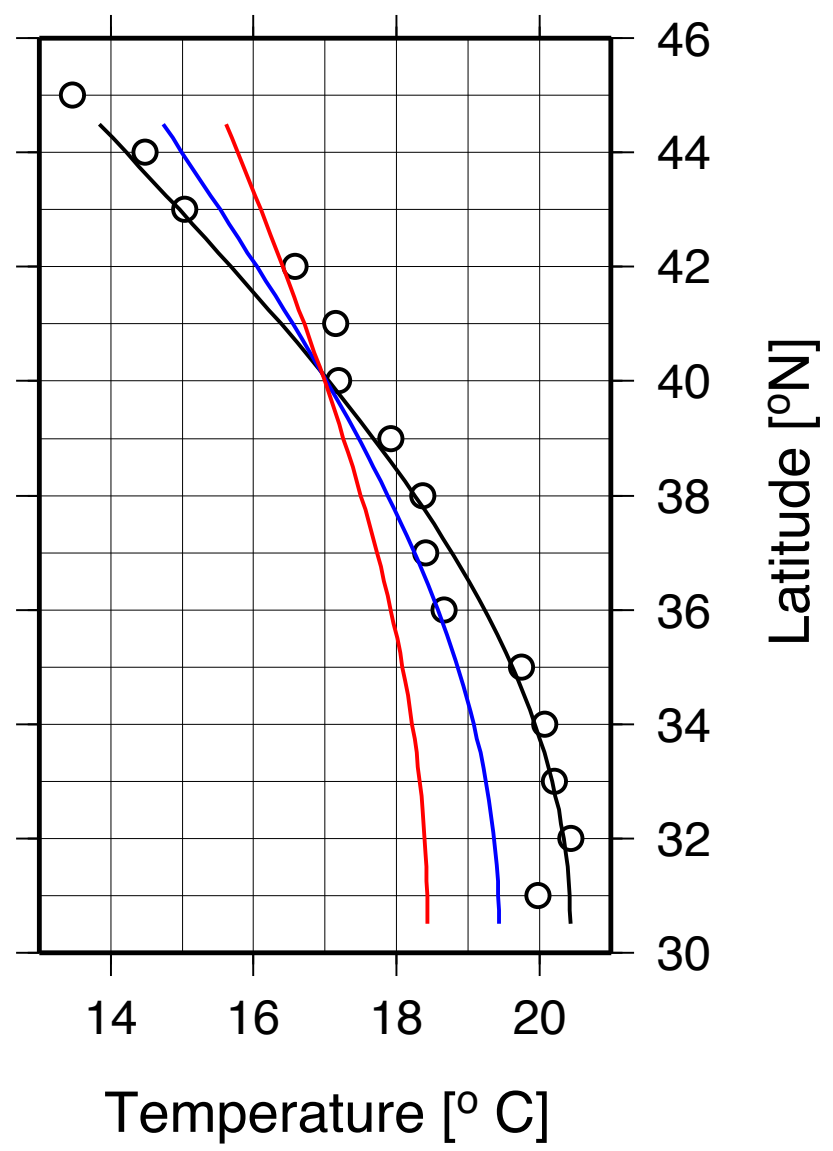

Fig. 1. Zonally averaged, annual-mean air temperature over the present-day Mediterranean Sea (circles) and its approximation by a cosine function of latitude (black line). The latter is used in the relaxation boundary condition on sea surface temperature. Data are from the ECMWF as processed by G. Korres, Athens (http://www. bo.ingv.it/mfstep). The blue and red line show the case of a reduced meridional temperature gradient used in producing the results of Fig. 4a.

The very fact that salinity stabilizes at some point suggests that the model captures the anti-estuarine exchange with the Atlantic Ocean: the salinity increase due to evaporation over the Mediterranean surface is compensated by an outflow of salty water at the ocean gateway (once inside the Atlantic "box" this water looses its salt through the volume relaxation applied there). This is confirmed by the zonal overturning streamfunction shown in Fig. 3a. This streamfunction conveniently displays the circulation on the (sub-)basin scale, this being the scale on which we may have most confidence in the idealized setup and also the scale of main interest when dealing with the geological past. Figure 3a shows water to flow eastward through the upper half of the Strait of Gibraltar and then east into the eastern basin where it sinks and turns westward at intermediate depth. Below this anti-estuarine upper cell, the eastern basin holds a deep cell that turns counterclockwise in this view: water sinks to great depth at about
Time $[\mathrm{yr}]$

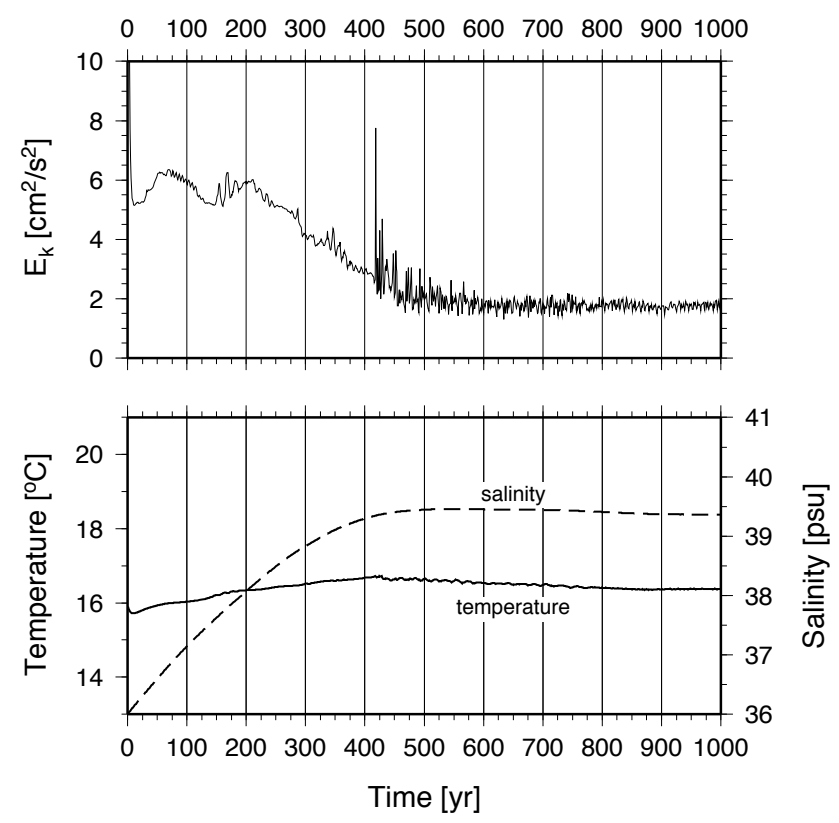

Fig. 2. Volume-averaged properties of the Mediterranean basin (i.e., from Gibraltar eastward) as a function of time for the reference experiment. Top panel shows a measure for mean kinetic energy (kinetic energy divided by density) and bottom panel gives average temperature (solid line, vertical scale at left) and salinity (dashed line, vertical scale at right).

$18^{\circ} \mathrm{E}$, in the Ionian basin just south of the Adriatic Sea, and then moves east and up to join the westward return flow at intermediate depth. Apart from a weak cell at about $9^{\circ} \mathrm{E}$ (in the Ligurian Sea, i.e., north of Corsica) the western Mediterranean does not contain a separate deep cell. Instead, the westward flow through the lower part of Sicily Strait sinks down before moving up and out to the Atlantic through the deeper portion of the Strait of Gibraltar.

The lack of a deep cell in the western basin is at odds with the observed present-day circulation (e.g., Pinardi and Masetti, 2000). For the rest and in particular for the eastern basin the model may be said to qualitatively capture the main features of the thermohaline circulation. In the southern Adriatic Sea and the adjacent part of the Ionian basin, as in other locations of relatively high latitude, the model shows continuous deep convection to occur, consistent with the imposed cooling of the surface water in these areas. The results show an outflow of dense water from the Adriatic Sea that feeds the deep cell in the eastern basin. Overall this is similar to the processes inferred to take place in reality (e.g., Pinardi and Masetti, 2000).

In order to assess the effect of the neglect of winds, the first experiment has been repeated with addition of a constant wind stress field derived by temporal averaging of modern observations (data from the European Centre for 

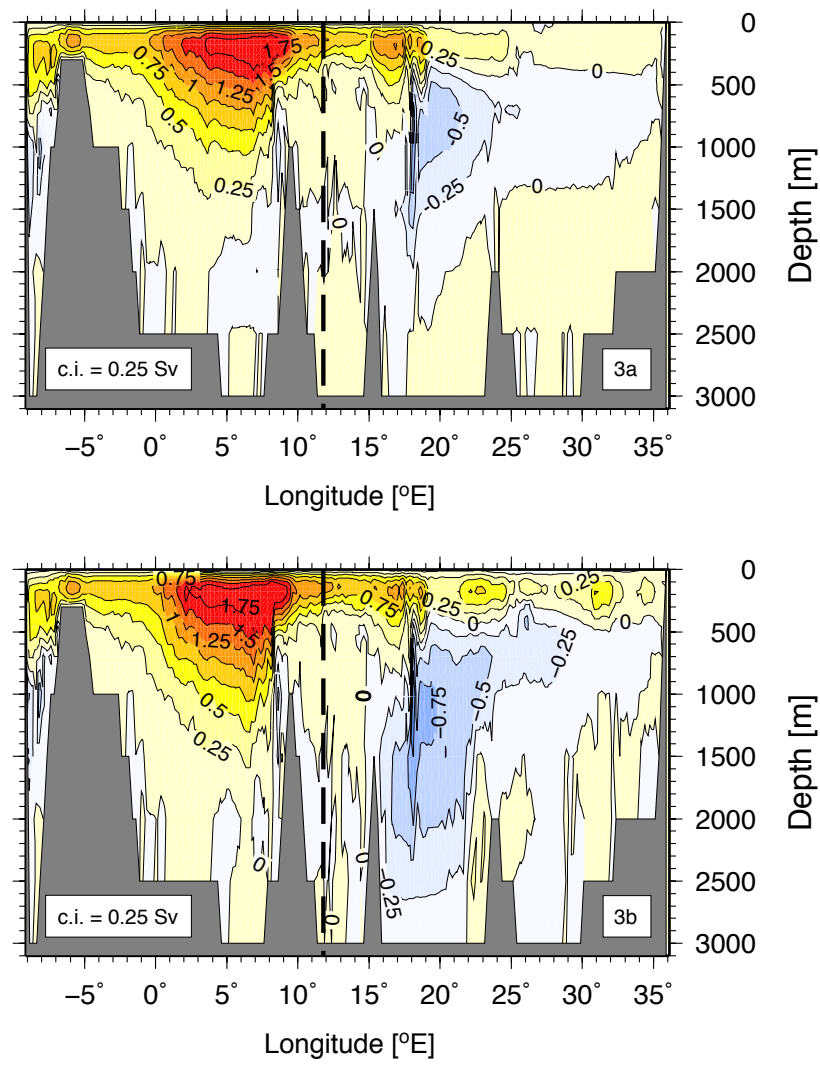

Fig. 3. Zonal overturning streamfunction based on the mean velocity field for years 901-1000. (a) Reference experiment; (b) same as reference run but with addition of wind stress. Contour values are in Sverdrup $\left(1 \mathrm{~Sv}=10^{6} \mathrm{~m}^{3} / \mathrm{s}\right)$; contour interval is $0.25 \mathrm{~Sv}$. Transport is along streamlines such that water moves clockwise around a streamfunction high. The bottom contour is defined by the deepest point at each longitude. The location of Sicily Strait, hidden by the deeper waters to the north of it, is indicated with a vertical dashed line.

Medium-Range Weather Forecasts as processed by G. Korres, Athens; http://www.bo.ingv.it/mfstep). While basinaverage temperature and salinity prove to be hardly affected, the zonal overturning streamfunction (Fig. 3b) shows an increase in strength of both the upper cell and the eastern deep cell. The first-order features of the modelled basin-scale circulation remain the same, however. Addition of the wind field does not improve the model's ability as to capturing the deep circulation of the western basin.

In comparison with overturning streamfunction results presented by Myers and Haines (2002) and Pisacane et al. (2006) it appears that the idealized setup somewhat overestimates the strength of the deep cell. This is true in particular having just seen that the addition of winds further strengthens the deep cell and knowing that our imposed net evaporation is the minimum of the estimated range for the present day ( 0.5 to $1.3 \mathrm{~m} / \mathrm{yr}$; compiled by Meijer and Krijgsman, 2005). One anticipates and, indeed, it is readily con- firmed by modelling, that larger values of net evaporation will lead to even stronger overturning. It is for this reason that net evaporation in our reference model is taken from the low end of the observed range. Quantitative differences between model and observations are likely due to the lack of seasonality in our setup. Increasing the time scale of relaxation of sea surface temperature to 1 day was found to only have a small effect. Finally, it is worth pointing out that the correct simulation of deep-water formation in the Mediterranean - in particular for the western basin - is known as difficult to achieve with basin-scale circulation models, also when these models involve more realistic atmospheric forcing schemes.

\subsection{Sensitivity to atmospheric forcing}

We examine the response of the deep cell in the eastern basin to two types of modification of the atmospheric forcing, both amounting to a decrease in buoyancy loss: (i) a reduction of the meridional atmospheric temperature gradient and (ii) a reduction in net evaporation, i.e., the equivalent of an increase in freshwater input. Changes in forcing are applied at the end of year 1000 of the reference run and then held constant.

If only to confirm the role of cooling over the Adriatic Sea in driving the deep cell, we first lower the imposed atmospheric temperature gradient. In reality this cooling is known to be one of the factors controlling deep-water formation in the Adriatic; it affects a water mass that is pre-conditioned through the inflow of salty intermediate water formed in the Levantine basin (Wu and Haines, 1996). The atmospheric temperature is modified by shifting the maximum (south) and minimum (north) value of the cosine function towards the mean, either by $1^{\circ} \mathrm{C}$ or by $2^{\circ} \mathrm{C}$ (Fig. 1). As a straightforward measure for the strength of the deep cell we use the minimum value of the streamfunction in the eastern part of the basin. Figure 4a shows that, in the reference experiment, the deep cell displays significant variability on different time scales even after 500 years of integration. Trends on the 100-year scale seem to relate to subtle variations in basin-averaged temperature and salinity and in the variability of mean kinetic energy (cf. Fig. 2). When, continuing from year 1000 of the reference run, the temperature gradient is suddenly reduced, the effect is an immediate reduction in strength of the deep cell. This is consistent with the notion that it is the cooling of surface water in the Adriatic Sea that results in an increase in density sufficiently strong to form deep water. With the first reduction in the temperature gradient (extremes shifted by $1^{\circ} \mathrm{C}$ ) we find that after about 200 years the deep cell has recovered its strength. In contrast, with a strong reduction in the gradient (extremes shifted by $2^{\circ} \mathrm{C}$ ) the deep cell appears to settle at a strength that is less than in the reference case. In both experiments the variability of the deep overturning resembles that of the reference case. 

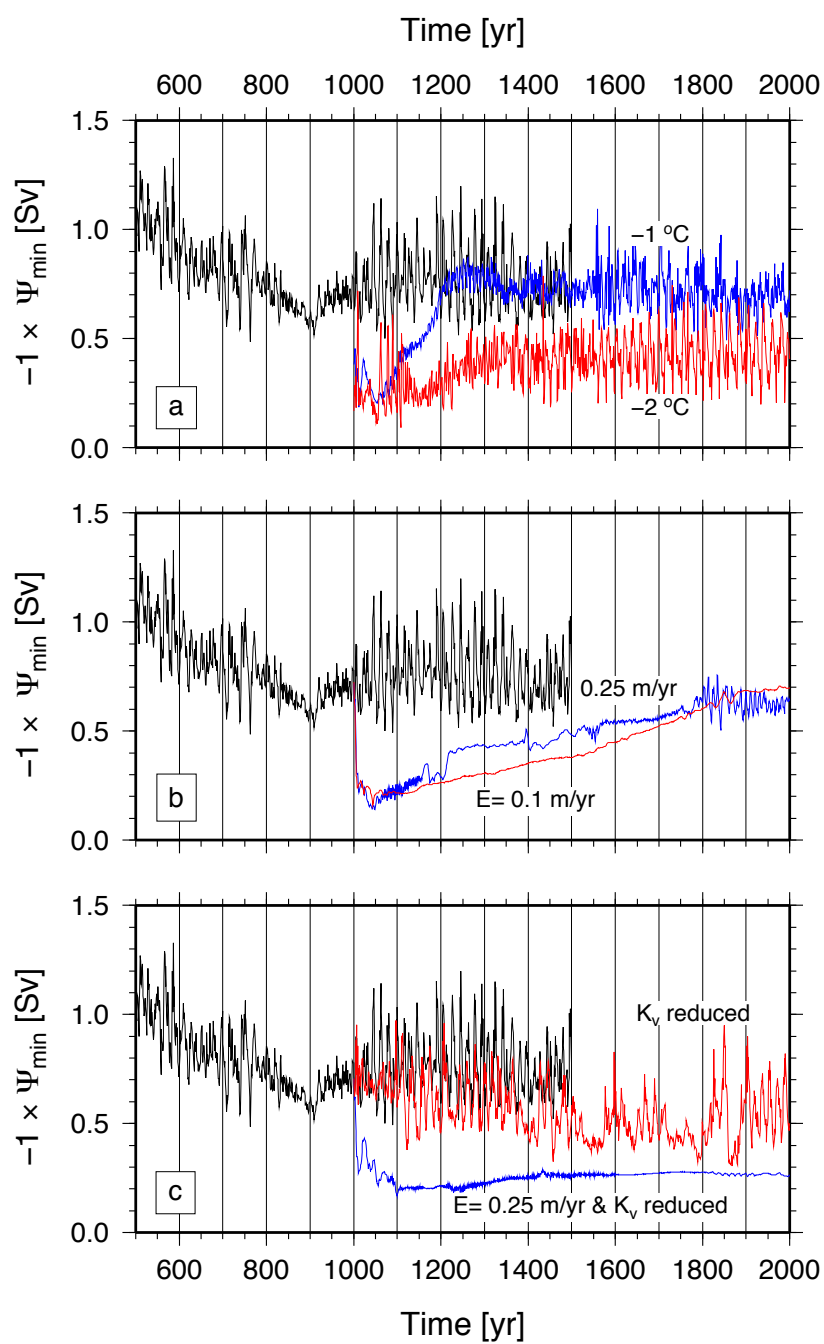

Fig. 4. Minimum of the zonal overturning streamfunction $\left(\Psi_{\min }\right)$, east of $18.5^{\circ} \mathrm{E}$ and deeper than $300 \mathrm{~m}$, as a function of time. This deep cell corresponds to negative values of the streamfunction; here we plot the strength multiplied by -1 to have "reduced strength" correspond to a line located lower down in the graph. (a) Black: reference experiment (continued until year 1500), blue: with temperature gradient reduced by shifting extremes by $1^{\circ} \mathrm{C}$ towards the mean, red: with temperature gradient reduced by shifting extremes over $2^{\circ} \mathrm{C}$. (b) Black: reference experiment (continued for 1500 years), blue: with reduction of net evaporation to $0.25 \mathrm{~m} / \mathrm{yr}$, red: with reduction of net evaporation to $0.1 \mathrm{~m} / \mathrm{yr}$. (c) Black: reference experiment, blue: with net evaporation reduced to $0.25 \mathrm{~m} / \mathrm{yr}$ and reduced vertical tracer diffusivity for layers below $300 \mathrm{~m}$, red: with only a reduction of the vertical tracer diffusivity.

Alternatively, once more starting from year 1000 of the reference experiment, we reduce the net evaporation from $0.5 \mathrm{~m} / \mathrm{yr}$ to $0.25 \mathrm{~m} / \mathrm{yr}$ (constant and uniform over the entire Mediterranean). We again find a sudden reduction in strength of the deep cell (Fig. 4b). In fact, the deep cell has effectively disappeared as shown in Fig. 5a. This situation is followed, however, by a period during which the deep cell slowly recovers (Fig. 4b). About 900 years after the change was imposed, the deep cell has regained significant variability about a long-term average that is slightly weaker than for the reference case (see also Fig. 5b). When we introduce - at year 1000 - a larger reduction in net evaporation (from $0.5 \mathrm{~m} / \mathrm{yr}$ to $0.1 \mathrm{~m} / \mathrm{yr}$ ) the response is similar: also in this case the deep cell regains strength over time (Fig. 4b). Recuperation of the deep cell is less pronounced, but still occurs, when we add wind stress to our experiments (examined only for a reduction of net evaporation to $0.25 \mathrm{~m} / \mathrm{yr}$; results not shown).

The initial response to a reduction in net evaporation is an effect of the associated decrease in sea surface salinity. Figure 6 shows the temporal evolution of average salinity at three model levels: $5 \mathrm{~m}$ (surface), $280 \mathrm{~m}$ (intermediate depth), and $2750 \mathrm{~m}$ (bottom). As shown in Fig. 6a, upon reduction of the net evaporation, the deeper layers initially retain their relatively high salinity. This implies that the density stratification becomes more stable which is consistent with the reduction in deep convection and halting of the deep overturning cell. When time proceeds, however, the deeper layers of the model can be seen to slowly decrease in salinity and hence, decrease in density, until at some point the density stratification is again favorable for deep overturning.

In the model, the deeper layers will mainly loose their salt by way of the assumed constant vertical diffusion of heat and salt. To test this interpretation we try lowering not only the general net evaporation to $0.25 \mathrm{~m} / \mathrm{yr}$ but also the value of the diffusivity constant for layers below $300 \mathrm{~m}$ (new value $0.25 \mathrm{~cm}^{2} / \mathrm{s}$ instead of $1.0 \mathrm{~cm}^{2} / \mathrm{s}$ ). In this case, at least for the duration of our experiment, we have decreased the strength of the deep cell. This follows from the strength of the deep cell as a function of time, shown in Fig. 4c, and is confirmed by the zonal streamfunction plots in Figures $5 \mathrm{c}$ and $5 d$. Figure $6 \mathrm{~b}$ shows the deep salinity to stay relatively high. Crucial to this behaviour is the combination of three factors: the reduced evaporation leading to a decrease in surface-water density, the reduced vertical diffusivity and the presence of relatively saline (dense) water at depth formed under the preceding conditions of higher net evaporation. If, at year 1000, we only introduce a reduction of the vertical diffusivity, the effect is found to be a limited reduction in the long-term average strength (Fig. 4c). In our model we need to adjust the value of the vertical tracer diffusivity as part of the setup; in reality it is likely that diffusivity will actually become less in response to the increased stratification that results from the reduction of net evaporation. It remains to be examined whether, in even longer integrations, also with small values of diffusivity the associated upward mixing of salt is perhaps sufficient to again destabilize the water column. 

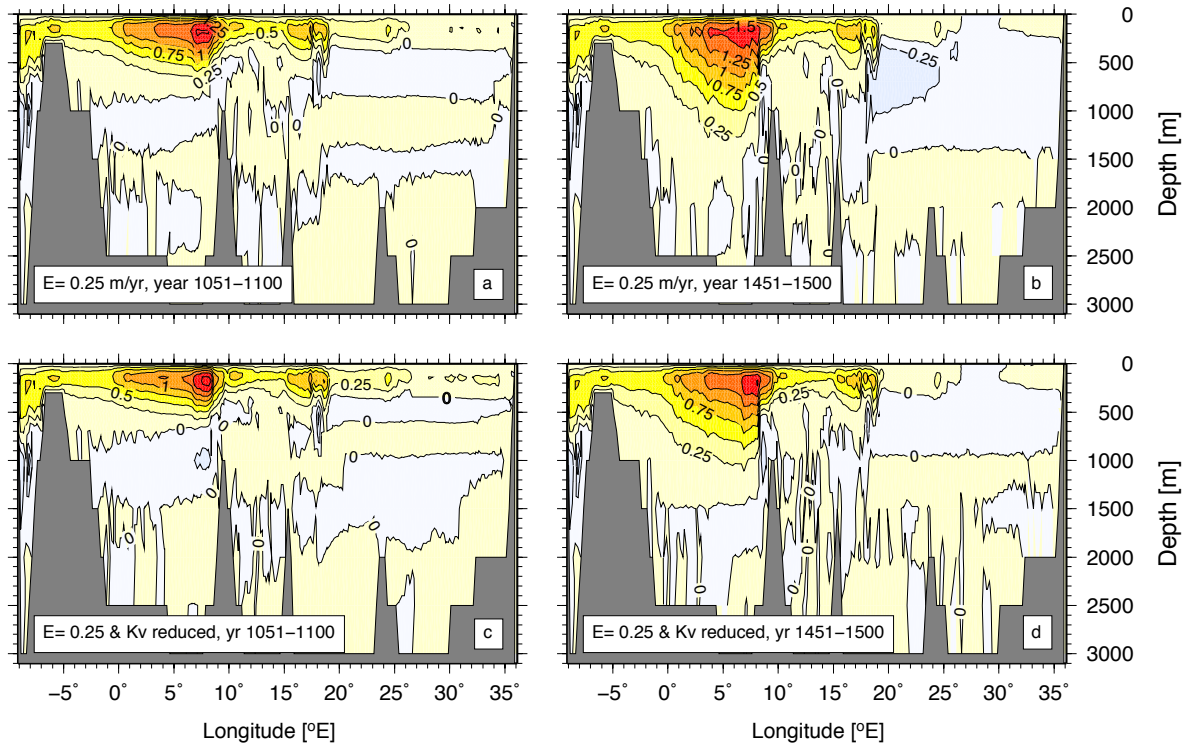

Fig. 5. Zonal overturning streamfunctions for different stages during two experiments. Contour interval is $0.25 \mathrm{~Sv}$. (a) For the case of a reduction of net evaporation to $0.25 \mathrm{~m} / \mathrm{yr}$, imposed at year 1000 (corresponding to the blue line in Fig. $4 \mathrm{~b}$ ) this panel shows the immediate response (average of years 1051-1100, i.e., 51-100 year after the change in forcing). (b) For the same experiment the situation after about 500 year (average of year 1451-1500). (c) For the case that both net evaporation and deep diffusivity are reduced (blue line in Fig. 4c). Average of year 1051-1100. (d) As previous for year 1451-1500.

\section{Discussion}

A "minimal" implementation of a general circulation model for the Mediterranean Sea has been shown to qualitatively capture major features of the basin-scale circulation, in particular for the eastern sub-basin. It is this type of model that, we propose, should be used as a starting point in studies of the effects of paleoclimate on Mediterranean circulation. The idealised setup also lends itself well to investigation of the effects of paleogeography, such as changes in basin geometry and in the depth of gateways. Future developments may include the use of more sophisticated parametrisations of processes such as horizontal mixing, but the possibilities will be limited by the implied increase in computation time.

As was previously concluded on the basis of modelling by Myers et al. (1998) and Myers (2002), we find that a reduction in net evaporation may indeed lead to the situation envisaged for the accumulation of organic-rich deposits. This leaves open the question how large the change in net evaporation entailed by the precession cycle actually is and whether it will be sufficiently large. Based on a climate model of intermediate complexity, Meijer and Tuenter (2007; see also Tuenter et al., 2003) report a reduction of $20 \%$, that is, smaller than the reduction we imposed in this paper. Larger reductions seem to be implied by reconstructions of sea surface salinity at times of sapropel deposition (summarized in Meijer and Tuenter, 2007). In any case, the idealised setup here advocated is probably best suited to investigate the qualitative nature of the response to a certain change in the boundary conditions and less so to quantitative aspects such as the determination of treshold values of net evaporation.

A very interesting avenue that the idealised setup does lead to, relates to the possibility of doing integrations on the order of several thousand years, in other words, for a significant part of the $\sim 21 \mathrm{kyr}$ long precession cycle. This allows one to actually "follow" the basin circulation into (or out of) the mode of sapropel formation. Recently, de Lange et al. (2008) presented a multi-variable reconstruction of the most recent sapropel $\left(\mathrm{S}_{1}\right)$ in the eastern Mediterranean at high temporal resolution. The combination of detailed records such as theirs with long runs with an idealised ocean model may offer interesting new insight. At this stage one point stands out. De Lange et al. (2008) are able to infer that sea surface salinity went down several hundreds of years prior to the onset of organic-rich deposition. We find that both surface salinity (Fig. 6) and deep-water overturning (Fig. 4) respond immediately to a reduction in net evaporation. This would suggest that the observed time lag results mostly from the time needed for the water properties (notably, oxygen content) to adjust to the reduced overturning until conditions favourable for sapropel formation are reached (examined by means of modelling by Stratford et al., 2000).

The ability to do long integrations leads to another interesting topic for further work: rather than imposing the reduction in net evaporation instantaneously one may consider spreading the extra freshwater input over a certain time span. Whereas we found that, upon instantaneous perturbation, the basin tends to recover its overturning over time (unless deep 

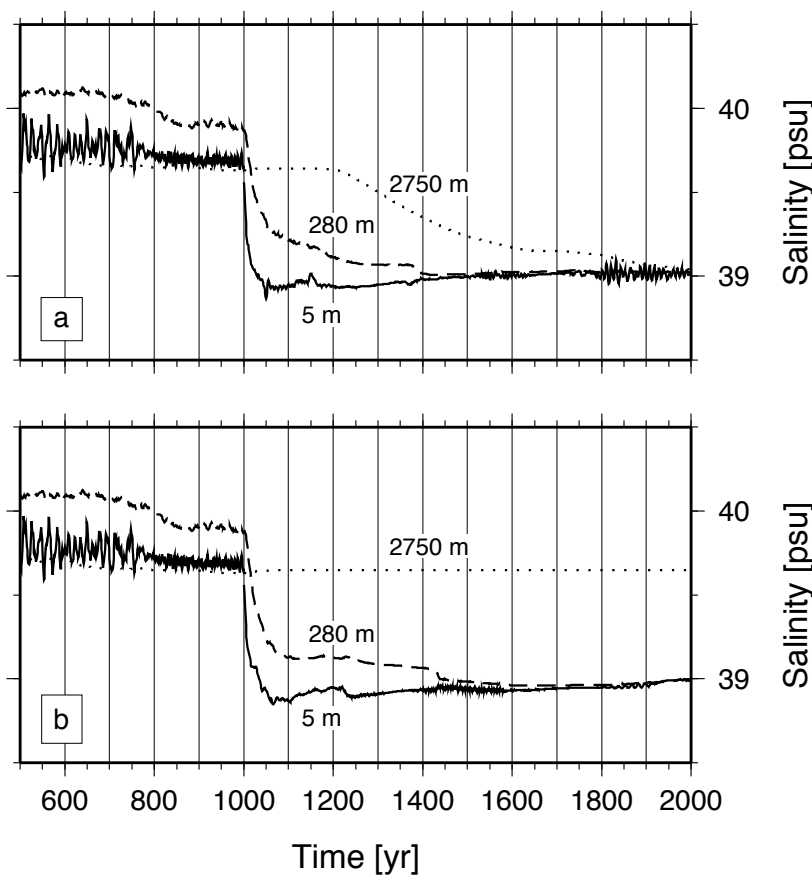

Fig. 6. Average salinity of the eastern Mediterranean basin as a function of time, at three model levels. Solid line refers to surface water $(5 \mathrm{~m})$; dashed line to intermediate depth $(280 \mathrm{~m})$, and dotted line to bottom water $(2750 \mathrm{~m})$. Up to year 1000 the lines correspond to the reference experiment, after that to a state with modified forcing. (a) The case of a reduction in net evaporation to $0.25 \mathrm{~m} / \mathrm{yr}$ (blue line in Fig. 4b). (b) The case of a reduction of both net evaporation and deep diffusivity (blue line in Fig. 4c).

vertical diffusivity is also reduced), this tendency may prove surpressed by the continuous addition of small amounts of fresh water.

\section{Conclusions}

The response of Mediterranean overturning to (i) a reduction in the imposed meridional temperature gradient and (ii) a reduction of net evaporation was found to be non linear and sometimes of transient nature. Consistent with previous model studies we find that a reduction in net evaporation (for example due to an increase in freshwater input) may give rise to the conditions favourable for sapropel formation. The merit of our analysis lies in the fact that it is based on a minimum of assumptions about the past atmospheric forcing and considers the response on a time scale that is a large multiple of the basin's residence time. In addition, our model experiments add the insight that vertical diffusivity plays a role.

Acknowledgements. We thank Bahjat Alhammoud and Pasha Karami for stimulating discussions and Bernd Haupt and an anonymous referee for providing constructive reviews. Figures have been prepared using GMT (Wessel and Smith, 1998). This research has been done in the context of the Utrecht Centre of Geosciences.

Edited by: U. Mikolajewicz

\section{References}

Cramp, A. and O'Sullivan, G.: Neogene sapropels in the Mediterranean; A review, Mar. Geol., 153, 11-28, 1999.

Emeis, K.-C. and Weissert, H.: Tethyan-Mediterranean organic carbon-rich sediments from Mesozoic black shales to sapropels, Sedimentology, 56, 247-266, 2009.

Haines, K. and Wu, P.: A modelling study of the thermohaline circulation of the Mediterranean Sea: Water formation and dispersal, Oceanol. Acta, 18, 401-417, 1995.

Hilgen, F. J.: Astronomical calibration of Gauss to Matuyama sapropels in the Mediterranean and implication for the geomagnetic polarity time scale, Earth Planet. Sci. Lett., 104, 226-244, 1991.

de Lange, G. J., Thomson, J., Reitz, A., Slomp, C. P., Principato, M. S., Erba, E., and Corselli, C.: Synchronous basin-wide formation and redoc-controlled preservation of a Mediterranean sapropel, Nature Geosci., 1, 606-610, 2008.

Lourens, L. J., Antonarakou, A., Hilgen, F. J., Van Hoof, A. A. M., Vergnaud-Grazzini, C., and Zachariasse, W. J.: Evaluation of the Plio-Pleistocene astronomical timescale, Paleoceanography, 11, 391-413, 1996.

Meijer, P. T. and Krijgsman, W.: A quantitative analysis of the desiccation and re-filling of the Mediterranean during the Messinian Salinity Crisis, Earth Planet. Sci. Lett., 240, 510-520, 2005.

Meijer, P. Th. and Tuenter, E.: The effect of precessioninduced changes in the Mediterranean freshwater budget on circulation at shallow and intermediate depth, J. Mar. Sys., doi:10.1016/j.jmarsys.2007.01.006, 2007.

Meijer, P. T., Slingerland, R., and Wortel, M. J. R.: Tectonic control on past circulation of the Mediterranean Sea: A model study of the Late Miocene, Paleoceanography, 19, PA1026, doi:10.1029/2003PA000956, 2004.

Meyers, P. A.: Paleoceanographic and paleoclimatic similarities between Mediterranean sapropels and Cretaceous black shales, Palaeogeogr. Climatol. Ecol., 235, 305-320, 2006.

Myers, P. G. and Haines, K.: Stability of the Mediterranean's thermohaline circulation under modified surface evaporative fluxes, J. Geophys. Res., 107(C3), 3021, doi:10.1029/2000JC000550, 2002.

Myers, P. G., Haines, K., and Rohling, E. J.: Modeling the paleocirculation of the Mediterranean: The last glacial maximum and the Holocene with emphasis on the formation of sapropel $\mathrm{S}_{1}, \mathrm{~Pa}-$ leoceanography, 13, 586-606, 1998.

Myers, P. G.: Flux-forced simulations of the paleocirculation of the Mediterranean, Paleoceanography, 17, 1-7, 2002.

Pinardi, N. and Masetti, E.: Variability of the large scale general circulation of the Mediterranean Sea from observations and modelling: A review, Palaeogeogr. Climatol., Ecol., 158, 153-174, 2000.

Pisacane, G., Artale, V., Calmanti, S., and Rupolo, V.: Decadal oscillations in the Mediterranean Sea: A result of the overturning circulation variability in the eastern basin?, Clim. Res., 31, 257271, 2006. 
Rahmstorf, S.: Multiple convection patterns and thermohaline flow in an idealized OGCM, J. Clim., 8, 3028-3039, 1995.

Rohling, E. J.: Review and new aspects concerning the formation of eastern Mediterranean sapropels. Mar. Geol., 122, 1-28, 1994.

Rohling, E. J. and Hilgen, F. J.: The eastern Mediterranean climate at times of sapropel formation: A review. Geologie en Mijnbouw, 70, 253-264, 1991.

Rossignol-Strick, M.: Mediterranean Quaternary sapropels, an immediate response of the African monsoon to variation of insolation, Palaeogeogr. Climatol. Ecol., 49, 237-263, 1985.

Roussenov, V., Stanev, E., Artale, V., and Pinardi, N.: A seasonal model of the Mediterranean Sea general circulation, J. Geophys. Res. C, 100, 13515-13538, 1995.

Schiermeier, Q.: A sea change, Nature, 439, 256-260, 2006.

Skliris, N., Sofianos, S., and Lascaratos, A.: Hydrological changes in the Mediterranean Sea in relation to changes in the freshwater budget: A numerical modelling study, J. Mar. Sys., 65, 400-416, 2007.

Stratford, K., Williams, R. G. and Myers, P. G.: Impact of the circulation on sapropel formation in the eastern Mediterranean, Glob. Biogeochem. Cy., 14, 683-695, 2000.
Toggweiler, J. R. and Russell, J.: Ocean circulation in a warming climate, Nature, 451, 286-288, 2008.

Tuenter, E., Weber, S. L., Hilgen, F. J., and Lourens, L. J.: The response of the African summer monsoon to remote and local forcing due to precession and obliquity, Glob. Planet. Change, 36, 219-235, 2003.

von der Heydt, A. and Dijkstra, H. A.: The effect of gateways on ocean circulation patterns in the Cenozoic, Global Planet. Change, 62, 132-146, 2008.

Webb, D. J.: An ocean model code for array processor computers, Comp. Geosci., 22, 569-578, 1996.

Wessel, P. and Smith, W. H. F.: New, improved version of Generic Mapping Tools released, EOS Trans. Amer. Geophys. U., 79(47), 579 pp., 1998.

Wu, P. and K. Haines, Modeling the dispersal of Levantine Intermediate Water and its role in Mediterranean deep water formation, J. Geophys. Res., 101, 6591-6607, 1996. 